\title{
Objective voice analysis for vocal polyps following microlaryngeal phonosurgery
}

Toran KC ${ }^{1}$, Lal BK²

${ }^{1}$ Associate Professor, ${ }^{2}$ Speech Language Pathologist, Department of ENT-HNS, Kathmandu Medical College, Sinamangal, Nepal

\begin{abstract}
Background: Vocal polyps are the products of voice overuse, misuse and abuse as the most common causative factors. Treatment generally advised for them are voice therapy and Microlaryngeal Phonosurgery (MLPS). The improved or changed quality of voice is generally assessed perceptually and can cause intra rater variability. In this study we compared and analysed the acoustic characteristics before and after MLPS.

Objective: The purpose of the study was to acoustically determine the changes in voice quality of a group of patients before and after the surgery.

Material and methods: The following patients group were studied prior to and in between 3 and 4 weeks of surgery. Altogether there were 23 patients with either unilateral or bilateral vocal polyps. Voice recording and analysis were performed with Dr. Speech acoustic software (Tiger electronics, USA). The parameters analyzed were in terms of perturbation (Jitter and shimmer), harmonic-to-noise ratio (HNR) and fundamental frequency $\left(\mathrm{F}_{0}\right)$.

Results: The results showed that shimmer, HNR and $\mathrm{F}_{0}$ decreased significantly $(\mathrm{p}<0.05)$ following MLPS, but jitter though reduced, was not statistically significant $(\mathrm{p}=0.694)$.

Conclusion: The acoustic output generally improved after MLPS as evidenced by decreased values of all the four acoustic parameters. The study also stress that voice quality can be improved through the phonosurgical procedures. This multidimensional voice analysis can be very helpful in our ability to provide objective clinical analysis of voices with vocal polyps, and following their surgical treatment.
\end{abstract}

Key words: Acoustic analysis, Vocal polyps, Micro-laryngeal phonosurgery

$\mathrm{V}$ ocal polyps are benign swellings usually on the anterior third of the vocal cord. They originate often on the free edge and usually are unilateral. They can be sessile or pedunculated ${ }^{1}$. There sizes may vary from a size of a pin head to a pea seed. They are usually caused by stress forces ${ }^{2}$. Their usual cause is vocal overuse, abuse (yelling) or even misuse (vocal trauma) ${ }^{3,4}$. All these factors leads to excessive mechanical stress and trauma in the mid membranous vocal fold with a wound formation remodelling of the superficial layer of lamina propria and to a lesser extent, the vocal fold epithelium, thereby forming a polyp $\mathrm{p}^{5,6,7}$.

Depending upon their microscopic characteristics, they also have been divided into fibrous polyps, telangiectatic polyps, and hyaline polyps ${ }^{3}$.

At the microscopic level certain molecular changes do occur in the extracellular matrix within the vocal folds polyps ${ }^{8}$. There is an up regulation of the gene for procollagen I, which is a marker for new collagen production. Moreover, Matrix metalloproteinases 12
$\& 1$, which are responsible for elastin breakdown and enzyme degradation, respectively are down regulated in the cases of vocal fold polyps. Paucity of hyaluronic acid in vocal fold polyps may be implicated in scar formation also. The up regulated expression of fibroprotein in polyps is associated with increased stiffness of the vocal fold lamina propria on videostroboscopy ${ }^{8}$.

The patients with vocal fold polyps usually complain of hoarse voice often with symptoms of vocal fatigue.

The mainstay in diagnosis of vocal fold lesion remains a thorough voice history followed by detailed imaging, perceptual and objective analysis.

Various form of objective and evaluation of normal and abnormal voice is being performed for last two decades.

Correspondence

Dr. Toran K.C.

Associate Professor

Kathmandu Medical College, Sinamangal, Kathmandu

E-mail: torankc@yahoo.com 
The computerized voice analysis tools allow clinicians to study the acoustic parameters of various types of voice disorders. The most important acoustic voice quality parameters used are fundamental frequency $\left(\mathrm{F}_{0}\right)$, perturbation (jitter and shimmer) and harmonicto-noise ratio (HNR). An altered or increased value of perturbation, $\mathrm{F}_{0}$ and $\mathrm{HNR}$ has been related to the various forms of voice disorders ${ }^{9,10}$, and 11 .

The goal of present study was to collect and analyze the acoustic qualities of voice in patients with vocal polyps and compare it with following microlaryngeal phonosurgery.

\section{Material and methods}

Twenty three patients with either unilateral or bilateral vocal polyps were included in the study. The study was conducted between March 2007 and April 2010. There were equal numbers of sexes with age ranging from 29 to 75 years with $43.9( \pm 12.3)$ years of mean age. Fifteen of the patients had unilateral vocal fold polyp. Following history taking laryngeal examinations were performed using both flexible fibre optic and videostroboscopic examinations. Following confirmation of the clinical diagnosis by the clinician and the speech language pathologist all the patients were subjected to acoustic voice analysis. Since the recording procedures and their analysis systems have appeared in the previous publications ${ }^{12}$, the methods are not described elaborately here. Following acoustic recording, voice therapy was provided at the voice clinic by the speech language pathologists. All the patients had received at least two therapies (one/week) before taking them up for the surgery.
Second sitting of vocal assessments were done between third and fourth week following microlaryngeal phonosurgery (MLSP). Those patients who did not meet the above criteria were omitted from the study. The acoustic samples were recorded with Dr. Speech software (Tiger Electronics, USA), in a sound treated room. The subjects were instructed to continuously utter the vowel //i// at the optimal pitch level and repeated several times. Recordings started as the patients vocal pitch level became habitual. Each subject's vowel was recorded three times, each for three seconds. The median value was considered for analysis. Four acoustic parameters analyzed were: fundamental frequency $\left(\mathrm{F}_{0}\right)$, jitter, shimmer and harmonic- to noise ratio (HNR).

Statistical analysis was performed with the SPSS 10.0 for windows (SPSS Corp., Chicago, IL).

\section{Results}

A total of 23 patients with variable degree of dysphonia due to vocal polyps requiring MLSP were included in the study. Total numbers of males and females were 12 and 11 respectively, with their mean age $43.9( \pm 12.3)$ years.

The acoustic analysis of the patients with vocal polyps before MLPS revealed the following mean resultsjitter $=0.20 \%$, shimmer $=2.18 \%, \quad H N R=23.97 \mathrm{~dB}$ and $\mathrm{F}_{0}=212.32 \mathrm{~Hz}$. Their data when recorded between third and fourth post operative weeks revealed lower values in all four acoustic parameters. The values are as presented in the table below. These group differences were statistically significance $(p<0.05)$ except for the jitter $(\mathrm{p}=0.694)$.

Table 1: Acoustic values before and after the surgery

\begin{tabular}{|l|c|c|c|c|} 
& Jitter (\%) & Shimmer (\%) & HNR(dB) & F $(\mathbf{H z})$ \\
A B B & A B & 2.181 .73 & 23.9722 .48 & 212.32196 .51 \\
\hline Mean & 0.200 .19 & 0.780 .38 & 3.703 .01 & 53.2348 .91 \\
\hline St. deviation & 0.100 .14 & 0.001 & 0.000 & 0.003 \\
\hline p-value* & 0.694 & & \\
\hline
\end{tabular}

* paired t-test applied, A: pre-operative values, B: post operative values. 


\section{Discussion}

Voice is an output of an extremely complex, multidimensional, and variable physiological phenomena. It is a result of aerodynamic and acoustic vibratory system. Due of these complexities in the production of voice it is not uncommon to find some degree of aperiodicity even in the normal voices. Since voice quality is diverse, it does not always provide an accurate and reproducible assessment. Nevertheless, it is one of the more controversial themes in vocal evaluation because there is a poor correlation between the evaluators. Thus, a voice with a sufficient grade of periodicity now can be analyzed with a computerized acoustic analyser, a relatively newer technique that is widely used in the clinical practice ${ }^{13,14,11}$.

The primary aim of this study was to collect acoustic data of voice in patients with vocal polyps, before and after MLPS and to evaluate the effectiveness of the surgery on the acoustic quality of voice. The four acoustic parameters that were selected were because of their frequent uses in several other studies ${ }^{15,16,17,18,19}$. Thus the selected parameters were jitter, shimmer, HNR and $\mathrm{F}_{0}$.

Jitter is a cycle to cycle variation in fundamental frequency of the voice ${ }^{20}$. Even a subtle micro instability in the vocal fold vibration will show changes in the jitter, which is true in the cases of vocal polyps ${ }^{21}$. Jitter also increases as the control over laryngeal muscle tone become coarser or as the number of active motor unit decreases ${ }^{22}$. In the study also jitter values were decreased from $0.20 \%$ to $0.19 \%$, however, without statistical significance $(\mathrm{p}=0.694)$

Shimmer is another measurement of perturbation. It refers to the small, rapid, cycle to cycle variation in the amplitude that occurs during phonation. These changes reflect even the slightest differences of mass, tension, biochemical characteristics as well as neural control over the vocal folds ${ }^{23}$. It also increases with poor and inconsistent contact between the vocal fold edges as occurs with a vocal polyps. This is the reason why the increased values of shimmer $(2.18 \% \pm 0.78)$ was reduced $(1.73 \% \pm 0.36)$ significantly $(\mathrm{p}=0.001)$ following MLPS. Uzola also found significantly reduced values of jitter and shimmer after MLPS ${ }^{24}$. In contrast to this study, there was only a significant decrease in shimmer, but not in jitter following MLPS, according to Zeitels et $\mathrm{al}^{25}$. But again Lin et al., has opined that percent jitter; but not percent shimmer is a reliable indicator when assessing a vocal lesion ${ }^{26}$. All these contradictions while assessing the perturbation attributable to methodological dissimilarity among the studies and application of different analytical systems and software for signal processing.
Another powerful indicator to quantify the quality of voice following voice treatment is $\mathrm{HNR}^{27}$. Thus a decreased HNR value was an important indicator to demonstrate the improved quality of voice in our study $(p=0.000)$. It shows decreased level of noise in the voice which should have occurred in any improved voice ${ }^{23}$. Similarly many other studies have revealed decrease in HNR values following surgery for vocal polyps ${ }^{28,29}$, and 30 . With improvement in all these parameters, the $\mathrm{F}_{0}$ also revealed remarkable improvement with increase in their pitch, bringing back the patients own vocal pitch. It is probably the tissue load that is important to lower the $\mathrm{F}_{0}$ value, as it is governed by the equation: $\mathrm{F}_{0}=1 / 2 \mathrm{~L} \sqrt{ } \sigma / \rho$ (where, $L=$ length of the vocal fold, $\sigma=$ surface density and $\rho=$ volume). Several other studies has observed decreased values of $\mathrm{F}_{0}$ following surgery for vocal polyps ${ }^{31,32,33}$. All these results suggested improved quality of voice following MLPS and were consistent for all the four acoustic parameters used in the study. In this respect, our findings supported the earlier studies ${ }^{19,33,34}$.

Our results also indicated that MLPS for vocal polyps leads to an improved quality of voice with decrease values of all the four acoustic parameters. Objective analysis of these parameters can provide clinicians a better understanding of vocal polyps on quality of voice and the benefits following MLPS.

\section{Conclusion}

The computerised voice analysis techniques provide an objective, reproducible and measurable data of vocal function. The dysphonic voice due to vocal polyps is documental and their improvements following MLPS are comparable. The study also reiterates the improvement of quality of voice following MLPS and when available, such methods should always be used.

\section{Acknowledgment}

The authors would like to thank Mr. Umesh Raj Aryal, lecturer from the Department of Community Medicine for his statistical assistance.

\section{References}

1. Dikkers FG, Nikkels PGJ. Benign lesions of the vocal folds: Histopathology and phonotrauma. Ann of Otol Rhinol and Laryngol, 1995;104:698703.

2. Johns, M. Michael. Update on the etiology, diagnosis, and treatment of vocal fold nodules, polyps, and cysts. Current opinion in Otolaryngology \& Head and Neck Surgery.2003;11 456-61. 
3. Mossallam L, Kotby MN, Ghaly AF et al. Histopathological aspects of benign vocal fold lesions associated with dysphonia. In: vocal fold histopathology. San Diego: College-Hill Press; 1986.

4. Chagnon F, Stone RE. Nodules and polyps. In: Organic voice disorders: Assessment and treatment. Wm.S. Brown, Jr, BP Vinson, MA Crary(Eds.). San Diego: Singular Publishing group Inc; 1996.

5. Gray S. Vocal fold physiology; acoustic. Perceptual and physiological aspects of Voice mechanisms. San Diego: Calif: Singular; 1989. p. 21-7.

6. Courey MS, Shohet JA, Scott MA et al. Immunohistochemical characterization of benign laryngeal lesions. Ann. Otol Rhinol. Laryngol. 1992;105:525-31.

7. Hirano, M, Bless DM: Videostroboscopic examination of the larynx. San Diego: Singular publishing group; 1993.

8. Thibeault SL, Gry SD, Li W et al. Genotypic and phenotypic expression of vocal fold polyps and Reinke's edema: a preliminary study. Ann Otol Rhinol laryngol. 2002;111:302-9.

9. Uloza V, Viktoras S, Ingrida U. Perceptual and acousticassessment of voice pathology and efficacy of endolaryngeal phonomicrosurgery. J of Voice. 2005; 19:138-45.

10. Geovani A, Revis J, Triglia JM. Objective, aerodynamic and acoustic measurement of voice improvement after phonomicrosurgery. Laryngoscope. 1999;109:656-60.

11. Yu P, Ouaknine M, Revis J, Giovanni A. objective voice analysis for dysphonic patients. A multiparametric protocol including acoustic and aerodynamic measurments. $\mathrm{J}$ of voice. 2001;15:(4):529-42.

12. $\mathrm{KC} \mathrm{T}$, Lal BK. Objective analysis of voice in normal young adults. Kumj. 2009;7:374-7.

13. Hirano M, Hibi S, Yoshida T et al., Acoustic analysis of pathological voice: some results of clinical applications. Acta Oto-laryngologica. 1988;105:432-8.

14. Larsson H, Hertegård S, Lindestad P, et al., Vocal fold vibrations: high-speed imaging, kymography, and acoustic analysis: a preliminary report. The Laryngoscope. 2009;110(12):211722.

15. Deliyski D. Acoustic model and evaluation of pathological voice production. Proceedings of the third conference on speech communication and technology Eurospeech 93. Berlin, Germany 1993.
16. Petrovic-Lazic M, Dobrota N, Jovanovic-Simic N. Multidimensional analysis of vowels in functioanal dysphonia. 27th world congress of the international association of Logopedics and phoniatrics, Technical University Denmark; 2007:173.

17. Doyle P, Perkell JS, Hammarberg B et al. Aerodynamic and acoustic voice measurements of patients with vocal nodules: variation in baseline and changes across voice therapy. J Voice. 2003;17:269-82.

18. Holmberg EB, Hillman RE, Hammarberg B et al. Efficacy of behaviorally based voice therapy protocol for vocal nodules. J voice. 2001;15:395-412.

19. HoriY. Jitter and shimmer in sustained observed in sustained phonation. Folia Phoniatr. 1985;37:81-6.

20. Key Elemetrics Corporation. MDVF Manual Version 2.7.0. Lincoln Park: Nj: Kay Elemetrics;1993.

21. Wolfe V, Martin D. Acoustic correlates ofdysphonia: type and severity. J Commun Disorder.1997;30:403-15.

22. Oguz H, Tarhan E, Korkmaz M, et al. Acoustic analysis findings in objective laryngopharyngeal reflux patients. J Voice. 2007;21:203-10.

23. Colton RH, Casper JK. Undrstanding voice problems: A physiological perspective for diagnosis and treatment. 2nd edition. Baltimore: Lippincott Williams \& Wilkins; 1996.

24. Uloza V. Effects on voice by endolaryngeal microsurgery. Euro. Arch Otolaryngol. 1919;256:231-315.

25. Zeitels SM, Hillman RE, DEsloge $\mathrm{R}$ et al. Phonomicrosurgery in singers and performing artists: treatment outcomes, management theories, and future directions. Ann Otol Rhinol Laryngol. 2002; 111:21-40.

26. Lin E, Jian JJ Hanson DG. Glottographic signal perturbation in biochemically different types of dysphonia. Laryngoscope. 1998; 108:18-25.

27. Yomoto E, Gould WJ, Baer T. Harmonicto-noise ratio as an index of the degree of hoarseness. J Acoustic Soc. Am.1982; 71:15441549.

28. Kim HT, Auo H, Office based $585 \mathrm{~nm}$ pulsed dye laser treatment for vocal ployps. Acta otolaryngologica, 2000;128:1043-7.

29. Kalusic SS, Horga D, Zrinski A longitudinal study of voice before and after phonosurgery for removal of a polyp. Clinical linguistics and phonetics. 2008;122: 857-63. 
30. Niedzielska G. Acoustic analysis in the diagnosis of voice disorders in children. Int $\mathrm{J}$ of Ped otolaryngol. 2001;57:189-93.

31. SM Jn, Song YK, Lee KC. The changes of voice quality following laryngeal microsurgery for vocal polyps and nodule. Korean OtolaryngolH \& N surgery.2003;46:147-50.

32. Katusic SS, Horga D, Zrinski KV. Longitudinal study of voice before and after phonosurgery for removal of a polyp. Clinical linguistics and phonetics 2008;22:857-63.

33. Petrovic-Lazic M, Babac S, Vukovic $M$ et al. Acoustic analysis of patients with vocal fold polyps. J Voice. 2010.[Epub ahead of print].

34. M.Behlau, G. Madazio, D. Feijo et al. Availico da Voz. In : M Behlau, Editor, Voz-O Livro do Especialista Vol.1. Rio de Janeiro: Revinter; 2010.p. 86-180. 